\title{
Anxiety and depression levels in patients with chronic orofacial pain
}

\section{Naomi Rahman ${ }^{1 *}$, Norma O'Connor ${ }^{2}$, Zaid Sadiq ${ }^{3}$ and Victor Lopes $^{4}$}

'BDS MFDS MOral Surg DClindent PgCAP AFHEA, Consultant in Oral Surgery, East Surrey Hospital, Canada Avenue, Redhill, RH1 5RH, United Kingdom

${ }^{2}$ BDS NUI, MFDS RCS Edin, M Clin Dent Oral Surg, M Oral Surg RCS Edin, FFD OS RCS Edin, Consultant in Oral Surgery, Edinburgh Dental Institute, Lauriston building, Lauriston Place, Edinburgh, EH9 3HA, UK

${ }^{3}$ Ph., D, B.D.S., M.B., Ch.B., F.R.C.S. Consultant in Oral \& Maxillofacial Surgery, University College London Hospital, 235 Euston Road, Fitzrovia, London, NW1 2BU, UK

${ }^{4}$ B.Sc., Ph., D, B.D.S., M.B., Ch.B., F.R.C.S., Consultant in Oral \& Maxillofacial Surgery, Edinburgh Dental Institute, Lauriston building, Lauriston Place, Edinburgh, EH9 3HA, UK

Received: 16 March, 2020

Accepted: 26 May, 2020

Published: 28 May, 2020

*Corresponding author: Dr, Naomi Rahman, Naomi Rahman, East Surrey Hospital, Canada Avenue, Redhill, RH1 5RH, UK, Tel: 07805264087;

E-mail: naomi136@msn.com

https://www.peertechz.com

\section{Check for updates}

\section{Abstract}

Introduction: Orofacial pain can be highly distressing, affecting $10 \%$ of the population and is associated with psychological symptoms. This study aims to assess the frequency of such psychological symptoms in orofacial pain patients compared to a control group and how these symptoms change with treatment. The effect of social deprivation will also be explored.

Method: We conducted a prospective study comparing 342 consecutive referrals to the pain clinic over a nine-year period with 100 controls. Exclusion criteria involved patients with dental/dentoalveolar pain or trigeminal neuralgia. The chronic faical pain patient's data was collected from validated questionnaires completed at every consultation. The somatic diagnoses were based on a interview process with one consultant conducting the pain clinic.

Results : The average age of patients and controls was 49.5 years. There was a statistically significant difference $(p=0.032)$ between the anxiety and depression scores respectively of patients (average $8.6 \& 6$ ) and controls $(6 \& 2.1)$. The pre-treatment anxiety scores were statistically significantly higher in improvers compared to non-improvers $(\mathrm{p}<0.05)$ but not with the depression scores.

Conclusion: Forty-two percent of patients reported improvement in their symptoms. A statistically significant correlation was found between anxiety and improvement following treatment, however not in depression scores. It is evident that while pain is managed effectively and anxiety is successfully reduced, depression is not treated. Deprivation is not a confounding factor in the experience of pain, anxiety, depression or improvement in symptoms. Therefore, treatment can be beneficial in reducing anxiety. However, this was not the case for depression scores and improvement following treatment and therefore it is unclear whether there was a psychological health benefit to these patients following treatment.

\section{Introduction}

For descriptive purposes we categorise pain into two groups: 1) Acute pain which acts physiologically to warn the body of an impending injury. 2) Chronic (pathological) pain which could be defined as pain which persists after the stimulus that induced it has resolved or pain which cannot be attributed to an obvious stimulus. Pain may be regarded as the sixth sense and it is widely accepted as the most common reason that patients seek healthcare advice. Chronic pain is widespread in the community and prevalence has been reported to range from $19 \%$ [1], to $53.8 \%$ [2], of the general population.

Orofacial pain represents a significant proportion of all chronic pain [3]. A systematic review of population based epidemiological studies of orofacial pain reported the median prevalence of orofacial pain affecting the population to be $13 \%$ [4]. In 2001, it was reported that facial pain affects at least $10 \%$ of the adult population and $50 \%$ of the elderly population [5]. 
Orofacial pain can be highly distressing and this is demonstrated by the model of the sensory homunculus, where a significant proportion of the cerebral hemisphere is represented by the head and in particular the lips and oral cavity. Orofacial pain includes dental, musculoskeletal, neurological and vascular pain. The majority of orofacial pain patients however will have more than one pain diagnosis at any given time [6]. Females are affected more commonly than males and the majority of patients are between 40 and 60 years of age [2]. The somatic, emotional and social wellbeing of this patient group is significantly affected by their chronic pain [2]. Depression rates of up to $50 \%$ and anxiety levels of $15 \%$ have been reported in this group of patients [7]. Pain therefore is a physiological sensation with components of emotional and psychological undertone. Psychosocial components of pain can either be an effect or driver of pain especially in the chronic pain state. An association between chronic orofacial pain and psychosomatic disorders including fibromyalgia, chronic fatigue syndrome, poor sleep, irritable bowel syndrome, dysmenorrhea and chronic back pain has been well documented $[5,7,8]$.

\section{In light of these findings the aims of this study were:}

a) To assess the levels of anxiety and depression in patients with chronic orofacial pain referred to a dedicated orofacial pain clinic in the United Kingdom

b) To compare levels of anxiety and depression of orofacial pain patients with a control group

c) To analyse any changes in symptoms following treatment along with post treatment anxiety and depression scores, to determine the presence or absence of any positive correlation

d) To determine if pre-treatment anxiety and depression scores, serve as a predictor of response to treatment

e) To assess the impact of deprivation on pain by using the Scottish Index of Multiple Deprivation (SIMD) scores or social deprivation of patients attending the Pain Clinic and to compare this to the control group

f) To assess the impact of deprivation on pain, specifically to examine for an association between SIMD score and presenting level of anxiety and depression.

\section{Methods}

This was a retrospective study comparing two groups. The test group was selected from consecutive patient referrals to the pain clinic over a nine-year period from March 2008 to March 2017. Exclusion criteria involved patients that received a diagnosis of organic dental/dentoalveolar pain or trigeminal neuralgia. A total of 342 patients were included in the study. For the test group data was collected retrospectively from questionnaires routinely completed at every consultation. The diagnoses were reached on the basis of a formal interview process with one Consultant conducting the Pain Clinic. The control group was selected from patients that were referred consecutively to the Combined Department of Oral and Maxillofacial Surgery and Oral Medicine, over a three-month period from March to May 2011 (Table 1). The demographics of the control group were matched with the test group in relation to age and gender, and patients were deemed suitable as controls if they answered "no" to the following two questions:

1. Do you have any pain in your head and neck?

2. Have you had any pain in your head and neck for the past 6 months?

A total of 100 patients were in the control group. Institutional approval was given for recruitment of the control group under local procedures for the conduct of audit and service review.

Anxiety and depression levels were quantified by the HAD (Hospital Anxiety and Depression) scale before treatment. The scale involves a 14-item self-administered rating scale consisting of 2 subscales: seven items measuring anxiety and seven items measuring depression [9]. A score of greater than 8 identifies possible and probable anxiety or depression with high sensitivity and specificity [10]. Scores from 10-14 are said to represent moderate anxiety or depression and scores $>15$ have been reported to represent severe disease [11]. The maximum score is 21 in each domain. A review of the validity of the HAD scale conducted in 2002 concluded that the HAD questionnaire performs at least as well as more comprehensive instruments used for identification of anxiety and depression [10].

Following treatment anxiety and depression levels of the pain group were analysed again as part of ongoing clinical practice. These levels were correlated with a reported improvement or lack of improvement of symptoms following treatment. Statistical analyses were carried out using the Statistical Package for the Social Sciences, Version 19.0 for Windows. Mann Whitney tests were carried out to compare anxiety and depression scores with controls and paired t-tests to compare scores pre and post treatment. Unpaired t-tests with Welch correction were carried out to compare pretreatment anxiety and depression scores in improved and not improved groups.

The postcodes of the test group were analysed by means of SIMD deciles from 2012 to derive deprivation status and compared to controls. Deciles were compared between patients without anxiety to those with moderate anxiety and severe anxiety. Also we compared the SIMD deciles between patients with moderate and severe anxiety. The same tests were carried out for depression. Treatment of pain patients included

Table 1: Demographics of pain patients and controls.

\begin{tabular}{|c|c|c|}
\hline & Pain patients & Controls \\
\hline Total no of patients & 342 & 100 \\
\hline Males & $70(20 \%)$ & $22(22 \%)$ \\
\hline Females & $272(80 \%)$ & $78(78 \%)$ \\
\hline Mean age (years) & 49.5 (range 16-87) & $50($ range 19-81) \\
\hline
\end{tabular}


medical management, cognitive behavioural therapy (CBT) and no active intervention.

In the test group there were 342 patients, $70(20 \%)$ males and $272(80 \%)$ females. The mean age was 49.5 years with a range of 16 to 87 years (Table 1 ).

\section{Results}

Their symptoms were classed as:

1) Persistent facial pain- $59 \%$

2) Temporomandibular joint dysfunction (TMD)- 35\%

3) Burning mouth syndrome- $6 \%$

At initial presentation, the mean anxiety score in pain patients was 8.5 , with a range of zero to 21 . The mean depression score for the pain group was 6.01 , with a range of zero to 20 (Figure 1). A total of $25 \%$ of the test group had an anxiety score of $10-14$ (mild to moderate anxiety) and $14 \%$ of test group had an anxiety score of more than 15 (moderate to severe anxiety.) In relation to depression, $15 \%$ of the test group had a score of 10-14 (mild to moderate depression) and 7\% had a depression score of greater than 15 (moderate to severe depression.) See summary in Table 2.

There were 100 controls which included $22(22 \%)$ males and $78(78 \%)$ females, with a mean age of 50 years (Table 1$)$. The mean anxiety score was 6 and the mean depression score was 2.1 (Figure 1). There was a statistically significant difference between the anxiety and depression scores in the pain group and the controls, with a p value $=0.032$ for anxiety and also depression, which is highly significant.

Treatment given to pain patients are summarised in Table 3.

In $42 \%(143)$ of pain patients there was a reported improvement in symptoms following treatment, 35\% (118) did not report improvement following treatment and in $24 \%$ (81) of cases the result was unknown as patients did not return for follow up (Table 4).

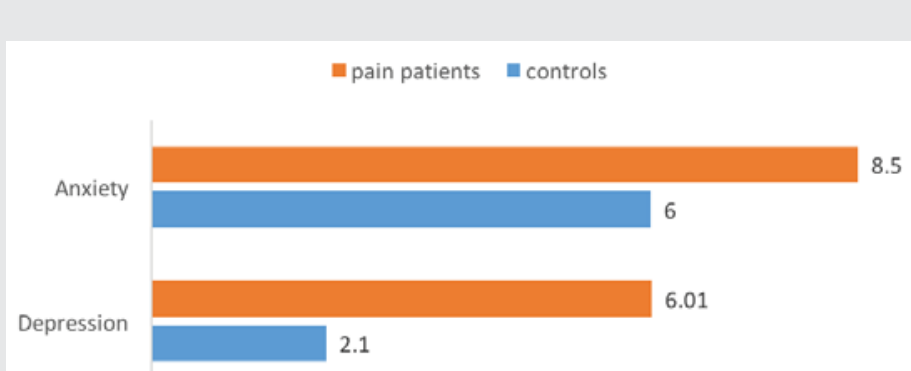

Figure 1: Anxiety and depression scores in pain patients and controls pre-treatment.

Table 2: Pre-treatment anxiety and depression scores of pain patients.

\begin{tabular}{|c|c|c|c|c|}
\hline $\begin{array}{c}\text { Pre-treatment } \\
\text { scores }\end{array}$ & $\begin{array}{c}\text { Anxiety: } \\
\mathbf{1 0 - 1 4}\end{array}$ & $\begin{array}{c}\text { Anxiety: } \\
>\mathbf{1 5}\end{array}$ & $\begin{array}{c}\text { Depression: } \\
\mathbf{1 0 - 1 4}\end{array}$ & $\begin{array}{c}\text { Depression: } \\
>\mathbf{1 5}\end{array}$ \\
\hline Pain patients & $25 \%(84)$ & $14 \%(49)$ & $15 \%(51)$ & $\mathbf{7 \%}(24)$ \\
\hline Control patients & $15 \%(15)$ & $5(5 \%)$ & $3 \%(3)$ & - \\
\hline
\end{tabular}

Table 3: Treatment given to pain patients

\begin{tabular}{|c|c|c|c|c|c|}
\hline Intervention & None & Medication & CBT & Surgery & $\begin{array}{c}\text { Unknown (not } \\
\text { recorded) }\end{array}$ \\
\hline $\begin{array}{c}\text { No of } \\
\text { patients }\end{array}$ & $\begin{array}{c}21 \% * \\
(72)\end{array}$ & $63 \% *(215)$ & $8 \% *(28)$ & $0.3 \% *(1)$ & $8 \% *(26)$ \\
\hline
\end{tabular}

*Percentages do not add up to $100 \%$ due to rounding of numbers

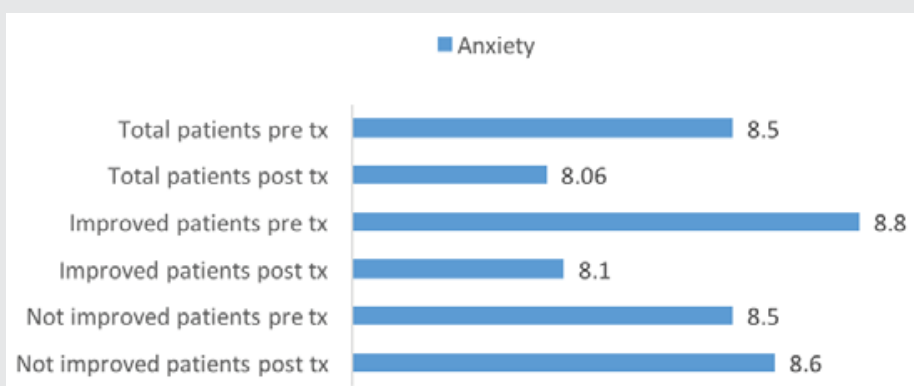

Figure 2: Anxiety levels pre and post- treatment.

Table 4: Improvement in symptoms following treatment.

\begin{tabular}{|c|c|c|c|}
\hline & $\begin{array}{c}\text { Improvement post } \\
\text { treatment }\end{array}$ & $\begin{array}{c}\text { No improvement post } \\
\text { treatment }\end{array}$ & Unknown \\
\hline $\begin{array}{c}\text { No of } \\
\text { patients }\end{array}$ & $42 \% *(143)$ & $35 \% *(118)$ & $24 \% *(81)$ \\
\hline *Percentages do not add up to $100 \%$ due to rounding of numbers
\end{tabular}

Following treatment, patients demonstrated an overall decrease in anxiety levels from a mean of 8.5 to 8.06 and this was statistically significant with a $\mathrm{p}$ value of $<0.05$ (Figure 2). Patients that reported improvement following treatment demonstrated a decrease in anxiety levels from a mean of 8.8 to 8.1 (Figure 2).

This decrease was not statistically significant, with a p value of 0.155 . In the patient group that showed no improvement in symptoms, the anxiety levels were slightly increased following treatment, from a mean of 8.5 to 8.6 (Figure 2). This increase again was not statistically significant, with a p value of 0.741 .

Overall the depression scores showed a slight increase, with a mean value of 6.01 pre-treatment and 6.17 post-treatment (Figure 3). Depression scores in the pain improved group pretreatment had a mean value of 6.4 and post-treatment slightly decreased to 6 , this was not statistically significant ( $\mathrm{p}$ value $0.338)$. In the pain non-improved group mean depression scores were 6.9 pre-treatment and post-treatment at $6.8(\mathrm{p}$ value 0.737 ) there was no statistically significant difference.

Differences in the pre-treatment anxiety scores in the improved and non-improved groups and also the pretreatment depression scores for the same groups were analysed using Mann-Whitney tests to assess statistical significance and are shown in Figure 4. This difference was not statistically significant for depression scores $(U=7886 \mathrm{p}$ value $=0.364)$. However, a statistically significant difference $(U=7086 \mathrm{p}$ value $=0.025$ ) was seen when comparing the pre-treatment anxiety scores in the improved and non-improved groups.

We also looked at the anxiety levels in males versus females, mean 8.76 , median 8 and found that there was no statistically 
significant difference between the two groups $(U=9208 \mathrm{p}$ value $=0.673)$. Similarly, the depression scores in males and females were not statistically different $(U=8982 \mathrm{p}$ value $=0.466)$.

The mean SIMD of patients attending the pain clinic was 6.53 (Table 5) and the mean SIMD of controls was 6.88, Mann-Whitney test showed that these two groups were not statistically significantly different $(p$ value $=0.32$. $)$

On comparison of SIMD deciles between patients without anxiety (mean 6.7, median 7 ) and those with moderate anxiety (mean 6.6, median 7) and severe anxiety (mean 6.3, median 7) as shown in Table 6, no statistical significance was found (Table 7).

On comparison of SIMD deciles between patients without anxiety (mean 6.7, median 7) and those with moderate anxiety (mean 6.6, median 7) and severe anxiety (mean 6.3, median 7) as shown in Table 6, no statistical significance was found (Table 7).

Similarly, no statistical significance in SIMD was detected between patients without depression (mean 6.67, median 7 )

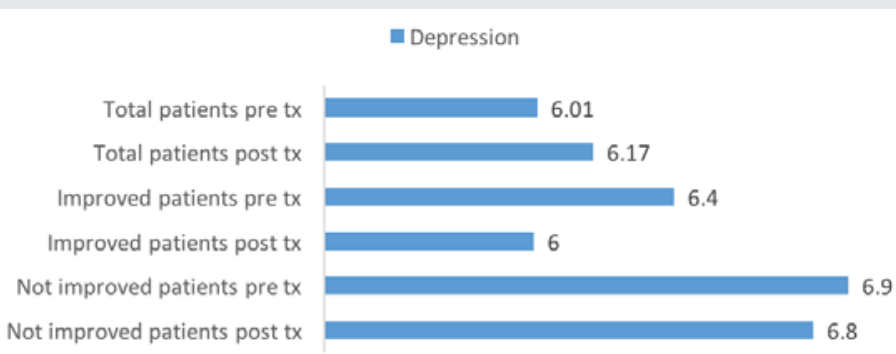

Figure 3: Depression levels pre and post-treatment

Improved not improved

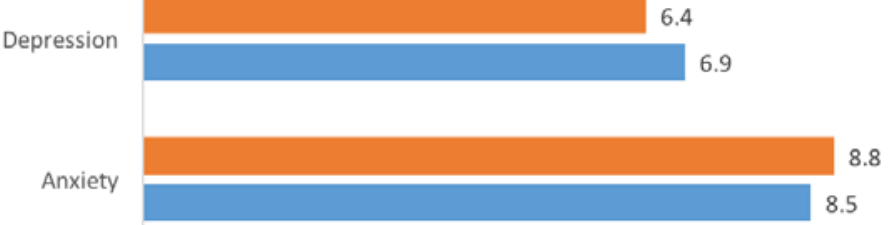

Figure 4: Depression levels pre and post-treatment.

Table 5: SIMD scores including the overall mean and the mean for improved and non-improved patients.

\begin{tabular}{c|c|c|c|}
\hline SIMD & Mean & Improved patients & Non improved patients \\
\hline 2012 decile & 6.53 & 6.78 & 6.53 \\
\hline
\end{tabular}

Table 6: SIMD scores for patients without anxiety (HAD score $<8$ ), with moderate anxiety (HAD score 10-14), with severe anxiety (HAD score $>15$ ) and SIMD scores for patients without depression (HAD score $<8$ ), with moderate depression (HAD score 10-14) and severe depression (HAD score $>15$ ).

\begin{tabular}{|c|c|c|c|c|c|c|}
\hline SIMD & $\begin{array}{c}\text { No } \\
\text { anxiety }\end{array}$ & $\begin{array}{c}\text { Anxiety: } \\
\mathbf{1 0 - 1 4}\end{array}$ & $\begin{array}{c}\text { Anxiety: } \\
\mathbf{> 1 5}\end{array}$ & $\begin{array}{c}\text { No } \\
\text { depression }\end{array}$ & $\begin{array}{c}\text { Depression: } \\
\mathbf{1 0 - 1 4}\end{array}$ & $\begin{array}{c}\text { Depression: } \\
\mathbf{> 1 5}\end{array}$ \\
\hline $\begin{array}{c}\mathbf{2} 2012 \\
\text { decile }\end{array}$ & 6.76 & 6.68 & 6.31 & 6.67 & 6.24 & 6.25 \\
\hline
\end{tabular}

Table 7: Mann Whitney tests comparing SIMD values between patients without anxiety to those with moderate and severe anxiety and comparing values between patients with moderate anxiety and severe anxiety.

\begin{tabular}{c|c|c|c|c|c|c|}
$\begin{array}{c}\text { Statistical } \\
\text { difference }\end{array}$ & $\begin{array}{c}\text { No } \\
\text { anxiety }\end{array}$ & $\begin{array}{c}\text { Moderate } \\
\text { anxiety }\end{array}$ & $\begin{array}{c}\text { No } \\
\text { anxiety }\end{array}$ & $\begin{array}{c}\text { Severe } \\
\text { anxiety }\end{array}$ & $\begin{array}{c}\text { Moderate } \\
\text { anxiety }\end{array}$ & $\begin{array}{c}\text { Severe } \\
\text { anxiety }\end{array}$ \\
\hline p value & 0.83 & \multicolumn{2}{|c|}{0.76} & \multicolumn{2}{|c|}{0.66}
\end{tabular}

Table 8: Mann Whitney tests comparing SIMD values between patients without depression to those with moderate and severe depression and comparing values between patients with moderate depression and severe depression.

\begin{tabular}{|c|c|c|c|c|c|c|}
$\begin{array}{c}\text { Statistical } \\
\text { difference }\end{array}$ & $\begin{array}{c}\text { No } \\
\text { depression }\end{array}$ & $\begin{array}{c}\text { Moderate } \\
\text { depression }\end{array}$ & $\begin{array}{c}\text { No } \\
\text { depression }\end{array}$ & $\begin{array}{c}\text { Severe } \\
\text { depression }\end{array}$ & $\begin{array}{c}\text { Moderate } \\
\text { depression }\end{array}$ & $\begin{array}{c}\text { Severe } \\
\text { depression }\end{array}$ \\
\hline p value & \multicolumn{2}{|c|}{0.51} & \multicolumn{2}{|c|}{0.79} & 0.47 \\
\hline
\end{tabular}

and those with moderate (mean 6.24, median 6) and severe depression (mean 6.25, median 8 ) and is shown in Table 8.

Finally, when the SIMD of improvers ( $n=143$, mean 6.78 , median 8) was compared to non-improvers $(n=118$, mean 6.53 , median 7) there was again no statistically significant difference, $\mathrm{p}$ value $=0.30$.

\section{Discussion}

Pre-treatment anxiety and depression scores observed in the cohort of patients presented here were 8.5 and 6.01 respectively. On comparison to other studies, slightly lower scores have been reported. In a study carried out by Giannakopoulos et al, the mean anxiety score in patients with TMD with or without chronic facial pain, was 5.6 and the mean depression score was $4^{12}$. A study of patients with chronic orofacial pain carried out by Galli et al in 2010, reported anxiety and depression scores at initial presentation of 7.76 and 5.72 respectively [19]. In our study, a statistically significant difference was evident between anxiety and depression scores of pain patients and controls. However, the biological relevance of this difference is questionable as the scores for the pain patients were generally low, with the mean anxiety score just exceeding the caseness threshold and the mean depression score falling within a normal range.

Anxiety refers to a relatively permanent future-focused state of worry and nervousness characterized by physical symptoms and it is usually accompanied by compulsive behaviour or attacks of panic [11]. Depression on the other hand is an affective disorder characterised by a pessimistic sense of inadequacy and a despondent lack of activity [11]. Pain is recognised as a subjective feeling engaging emotional and affective components and is more complex than a mere physical sensation event signalling tissue damage [10]. Genetic predisposition, heightened anxiety and depression combined with certain environmental factors all play an important role in the development of chronic pain conditions [12]. In their article reclassifying myofascial pain as persistent orofacial muscle pain (POMP) the authors described 'a complex disease model' for chronic facial pain just like other persistent pain conditions [13]. It is well established that persistent pain may lead to neuroplastic changes within the peripheral and central nervous system [14], a process known as central sensitisation. Mounting evidence suggests that regional pain syndromes, including TMD, fibromyalgia, irritable bowel syndrome, 
headaches, chronic lower back pain and chronic neck pain share this common pathological process [15]. This evidence is strengthened by the fact that these disorders often co-exist and also serve as risk factors for each other [12].

With this in mind, the management of patients with chronic orofacial pain or POMP, it is important to address and minimise psychosocial elements or morbidities in an attempt to optimise treatment success. Mongini et al reported that anxiety increases the likelihood of muscle tenderness and facial pain [16]. Madland et al looked at patients with facial arthromyalgia and reported that increased levels of pain lead to elevated anxiety scores [17]. On the other hand, a recent study looking at patients with anxiety and depression demonstrated that patients with co-existing pain are more prone to chronic anxiety and/or depression and an overall poorer disease progression [18]. It recommended to pay more attention to pain in the management of these patients.

Optimal management of chronic orofacial pain patients involves input from a multidisciplinary team of healthcare workers [20, 21]. Unfortunately, availability of this skill set within one team is rarely a reality.

The mainstay of treatment involves medical management and some CBT. The most commonly used drugs, including tricyclic antidepressants, anticonvulsants, Botulinum toxin, muscle relaxants and benzodiazepines, have not been validated in controlled clinical trials for this indication [22]. However anecdotal evidence suggests that low dose of benzodiazepines for a short period in acute spasmodic state taken at night can induce muscle relaxation and improved sleep and offers respite while long acting neuropathic analgesia like tricyclic antidepressants have time to work.

In our study just under half of the test group reported improvement following treatment. However, looking at the anxiety scores following treatment in these improved patients, there was a statistically significant difference noted on comparison with pre-treatment scores. The pre-treatment depression scores were not statistically significant following treatment in the improved group. Therefore, it is evident that while the pain is managed effectively and improvement in symptoms and anxiety is successfully achieved, depression is not treated and remains unchanged.

The Scottish Index of Multiple Deprivation 2012 [23], provides a relative measure of deprivation across all of Scotland. It combines 38 indicators across 7 domains, namely: income, employment, health, education, skills and training, housing, geographic access and crime. The overall index is a weighted sum of the seven domain scores. Although it is well recognised that lower socioeconomic status and markers of social disadvantage, correlate with increased chronic pain prevalence and intensity $[6,24]$, in this study the SIMD did not demonstrate any statistical significance between pain patients and controls and also between patients with varying degrees of anxiety and depression.

\section{Conclusion}

The patients investigated in this study experienced higher levels of anxiety and depression to other published studies. There was a statistically significant correlation between anxiety scores and improvement following treatment. Therefore, treatment can be beneficial in reducing anxiety. However, this was not the case for depression scores and improvement following treatment and therefore it is unclear whether there was a psychological health benefit to these patients following treatment. In accordance with current quality assurance standards, it would be desirable to follow-up this study with a health outcome based assessment to analyse the relevant effect of the current treatment regimens.

\section{Informed consent}

Verbal informed consent was obtained from all subjects before the study. Written informed consent was not obtained because the study was part of an ongoing service review.

\section{Ethical approval}

Ethical approval was not sought for the present study because the study was part of an ongoing service review. However institutional approval was given for recruitment of the control group under local procedures for the conduct of audit and service review. This study was completed in accordance with the Helsinki Declaration as revised in 2013.

\section{References}

1. Breivik H, Collett B, Ventafridda V, Cohen R, Gallacher D (2006) Survey of Chronic Pain in Europe: Prevalence, impact on daily life and treatment. Eur $\mathrm{J}$ Pain 10: 287-333. Link: https://bit.ly/2X26XVZ

2. Elliott AM, Smith BH, Hannaford PC, Smith WC, Chambers WA (2002) The course of chronic pain in the community: results of a 4-year follow-up study. Pain 99: 299-307. Link: https://bit.ly/2yxqBjg

3. MacFarlane TV, Blinkhorn AS, Davies RM, Ryan P, Worthington HV, et al. (2002) Orofacial Pain: Just another chronic pain? Results from a population based survey. Pain 99: 453-458. Link: https://bit.ly/3entZg6

4. Macfarlane TV, Glenny AM, Worthington HV (2001) Systematic review of population based epidemiological studies of orofacial pain. J Dent 29: 451467. Link: https://bit.ly/2MbONuZ

5. Madland G, Newton-John T, Feinman C (2001) Chronic Idiopathic Orofacial Pain:1: What is the evidence base? Br Dent J 191: 22-24. Link: https://bit.ly/2TDzQG4

6. Zakrzewska JM (2009) Orofacial pain. In: Drangsholt M, LeResche L, editors Orofacial Pain. Oxford, New York: Oxford University 1-9.

7. Aghabeigi B, Feinmann C, Glover V, Goodwin B, Hannah P, et al. (1993) Tyramine conjugation deficit in patients with chronic idiopathic temporomandibular joint and orofacial pain. Pain 54: 159-163. Link: https://bit.ly/2LXHRRI

8. Ingemar Andersson $\mathrm{H}$ (2004) The course of non-malignant chronic pain: a 12 year follow up of a cohort from the general population. Eur J Pain 8: 47-53. Link: https://bit.ly/3d35qor

9. Giannakopoulos NN, Keller L, Rammelsberg P, Kronmuller KT, Schmitter M (2010) Anxiety and depression in patients with chronic temporomandibular pain and in controls. J Dent 38: 369-376. Link: https://bit.ly/2M0TzeE 
10. Koyama T, McHaffie JG, Laurienti PJ, Coghill RC (2005) The subjective experience of pain: where expectations become reality. Proc Natl Acad Sci USA 102: 12950-12955. Link: https://bit.ly/2TEsimy

11. Diatchenko L, Nackley AG, Slade GD, Fillingim RB, Maixner W (2006) Idiopathic pain disorders: Pathways of vulnerability. Pain 123: 226-230. Link: https://bit.ly/2TElaFu

12. Benoliel R, Svensson P, Heir GM, Sirois D, Zakrzewska J, et al. (2011) Persistent orofacial muscle pain. Oral Dis 17: 23-41. Link: https://bit.ly/2M2WZxq

13. Kindler LL, Bennett RM, Jones K (2011) Central Sensitivity Syndromes: Mounting Pathophysiologic Evidence to Link Fibromyalgia with Other Common Chronic Pain Disorders. Pain Manag Nurs 12: 15-24. Link: https://bit.ly/36vP2tT

14. Gerrits MM, Vogelzangs N, van Oppen $P$, van Marwijk HW, van der Horst $H$, e al. (2012) Impact of pain on the course of depressive and anxiety disorders. Pain 153: 429-436. Link: https://bit.ly/2TUTBZZ

15. Mongini F, Ciccone G, Ceccarelli M, Baldi I, Ferrero L (2007) Muscle tenderness in different types of facial pain and its relation to anxiety and depression: a cross-sectional study on 649 patients. Pain 131: 106-111. Link: https://bit.ly/2ZEwhTM

16. Madland G, Feinmann C, Newman S (2000) Factors associated with anxiety and depression in facial arthromyalgia. Pain 84: 225-232. Link: https://bit.ly/3d5eLf8
17. Gerrits MM, Vogelzangs $N$, van Oppen $P$, van Marwijk HW, van der Horst $H$, et al. (2012) Impact of pain on the course of depressive and anxiety disorders. Pain 153: 429-436. Link: https://bit.ly/2TUU9z1

18. Galli U, Ettlin DA, Palla S, Ehlert U, Gaab J (2010) Do illness perceptions predict pain-related disability and mood in chronic orofacial pain patients? A 6-month follow-up study. Eur J Pain 14: 550-558. Link: https://bit.ly/36vEz1x

19. Zakrzewska JM (2013) Differential diagnosis of facial pain and guidelines for management. Br J Anaesth 111: 95-104. Link: https://bit.ly/2TGDYVF

20. Hals EKB, Stubhaug A (2011) Mental and somatic co-morbidities in chronic orofacial pain conditions: Pain patients in need of multiprofessional team approach. Scand J Pain 14: 153-154. Link: https://bit.ly/2Xsj8dK

21. Zakrzewska JM (2009) Overall management of facial pain. In: Raymond Dionne R, Newton-John T, Zakrzewska J, editors. Orofacial Pain. Oxford, New York: Oxford University Press 53

22. Scottish Governmen (2018) Scottish Index of Multiple Deprivation, Edinburgh Scottish Government 2012. Link: https://bit.ly/2TE6gjv

23. Blyth FM, March, LM, Brnabic AJM, Jorm LR, Williamson M, et al. (2001) Chronic pain in Australia: a prevalence study. Pain 89: 127-134. Link: https://bit.ly/2MOhvyA

24. Yazdi M, Yilmaz Z, Renton T, Page L (2012) Psychological morbidity in chronic orofacial pain and headaches. Oral Surgery 5: 173-181. Link: https://bit.ly/2B5S2Sp

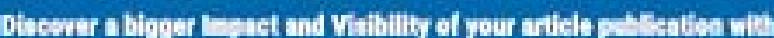 Peertechr Publications}

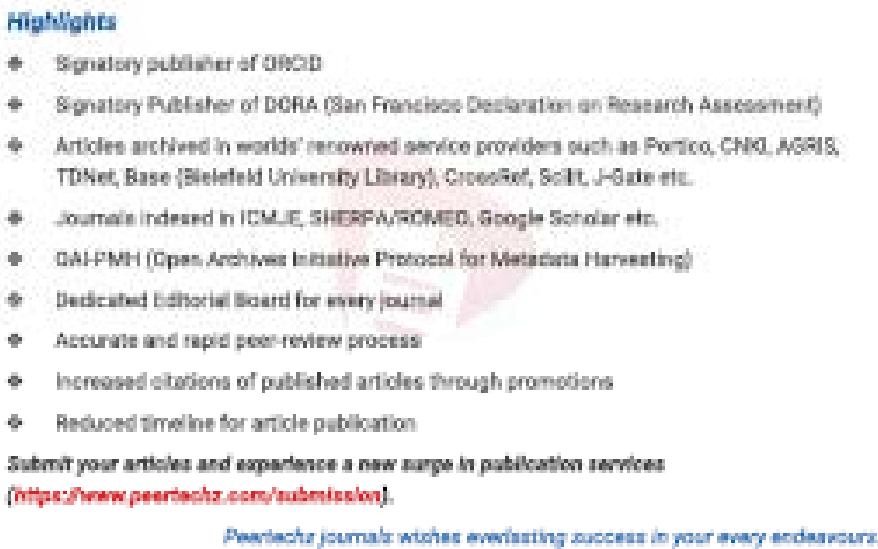

Copyright: (c) 2020 Rahman N. This is an open-access article distributed under the terms of the Creative Commons Attribution License, which permits unrestricted use distribution, and reproduction in any medium, provided the original author and source are credited. 